\title{
The intake and quality of breakfast consumption in adolescents attending public secondary schools in the North West province, South Africa
}

\author{
Tee L, ${ }^{1}$ MSc Nutrition, Student; Botha C,' PhD, HMS, Senior Lecturer \\ Laubscher R, ${ }^{2}$ BCom(Maths), Biostatistician; Jerling J, ${ }^{1} \mathrm{PhD}$, Professor \\ Centre of Excellence for Nutrition, North-West University, Potchefstroom \\ ${ }^{2}$ Biostatistics Unit, Medical Research Council, Tygerberg \\ Correspondence to: Chrisna Botha, e-mail: chrisna.botha@nwu.ac.za \\ Keywords: adolescent, breakfast, breakfast quality, diet quality, adolescence
}

\section{Abstract}

Objectives: The objectives of the study were to determine the proportion and quality of breakfast intake in adolescents, and to determine the effect of breakfast intake and quality on overall diet quality.

Design: A cross-sectional quantitative study design was used.

Setting: The setting was seven public secondary schools in Potchefstroom and the surrounding areas in North West province.

Subjects: The subjects were randomly selected adolescents in grades 9-11 $(n=244)$.

Outcome measures: A self-administered demographic questionnaire was completed by the adolescents. Single 24-hour recall, using the four-stage multiple-pass method, was conducted to obtain information on breakfast and dietary intake for the day. Breakfast quality was measured by applying a breakfast quality score. The Diet Quality Index Revised was used to assess the quality of the overall diet. Spearman's rank correlation coefficient was employed to assess an association between the continuous variables. The chi-square or Fisher's exact test was utilised to assess an association between the categorical variables.

Results: The proportion of breakfast intake and skipping was $81 \%$ and $19 \%$, respectively. The mean breakfast quality score was moderate (3.1). No significant difference was shown in the diet quality score for the breakfast eaters and skippers. The breakfast quality score was marginally associated with calcium intake ( $p$-value $<0.0001, r=0.418$ ), phosphorous intake ( $p$-value $<0.0001, r=0.378$ ) and total diversity score $(p$-value $<0.0001, r=0.369)$.

Conclusion: The proportion of breakfast skipping, moderate quality of the breakfast consumed and trend of improved nutrient intake with improved breakfast quality highlights the need for breakfast education and intervention as part of the Integrated School Health Policy.

(P) Peer reviewed. (Submitted: 2014-10-03. Accepted: 2015-01-27.) ๑ SAJCN

S Afr J Clin Nutr 2015;28(2):81-88

\section{Introduction}

Regular breakfast consumption by adolescents has been linked to a decreased risk of obesity and chronic diseases, improved cognition and improved nutrient intake. ${ }^{1-5}$ Despite this, research has indicated that adolescent breakfast consumption is declining globally. ${ }^{6-8}$ The reported prevalence of breakfast skipping in different adolescent population groups in South Africa ranges from 13-36\%. ${ }^{9-11}$

Adolescents are at particularly high risk of health-compromising behaviour, such as increased fast food consumption, increased sedentary levels and frequent breakfast skipping. ${ }^{12,13}$ Getting adequate exercise and sleep, maintaining a healthy weight, not smoking or binge drinking, and eating breakfast regularly, decline dramatically in the transition to young adulthood. ${ }^{12,13}$ Research shows that lifestyle and behaviour habits that become entrenched in adolescence are likely to remain throughout adulthood. ${ }^{14}$

Understanding the magnitude of the problem to be addressed can be obtained by studying the prevalence of breakfast skipping and the quality of breakfast consumed within a particular target group. Understanding how breakfast intake and quality influence health outcomes guides effective recommendations for breakfast intake, which can be used in public health guidelines and intervention programmes. ${ }^{15,16}$

The aim of this study was to determine the proportion of adolescents eating breakfast, the quality of the breakfast consumed, and the effect of the breakfast intake and quality on overall diet quality and other lifestyle behaviour in adolescents attending public secondary 
schools in Potchefstroom and surrounding areas in the North West province of South Africa.

\section{Method}

\section{Research design}

A cross-sectional quantitative design was used for the study.

\section{Study participants and sampling}

The study focused on randomly selected adolescents, both boys and girls, attending seven public secondary schools in grades 9-11, and residing in the urban and peri-urban areas of Potchefstroom and surrounding areas in the North West province of South Africa. Secondary schools were entered into the eligibility pool for selection $(n=19)$. The schools were stratified for quintile (1-5), and then one school from each quintile was randomly selected using a randomiser tool. South African schools are divided into five categories or quintiles based on their poverty ranking. ${ }^{17}$ Quintile 1 represents the poorest schools, and quintile 5 the least poor. ${ }^{17}$ This classification is determined through implementation of a national poverty table which establishes the poverty ranking of areas based on information from the national census and the catchment area of the school. ${ }^{17}$ Schools from all of the quintiles were included in the study to ensure that an equal distribution of children attending different kinds of schools was represented, and that the research was not biased to one group of adolescents.

It was calculated that data from 50 students from each quintile would be required to determine accurate means, standard deviation and to be able to compare quintiles. This was not proportional or representative of the total population in Potchefstroom and surrounding areas. A list of students in grades 9-11 was obtained from each school, and the students were randomly selected to take part in the study using a randomiser tool. Too few participants were available on the day of data collection from the schools in quintiles 4 and 5 owing to unreturned consent forms. Therefore, a second school representing each of these quintiles was selected, resulting in a total of seven schools being included in the study. A total of 254 adolescents was recruited.

\section{Data collection}

A self-administered demographic questionnaire was used to obtain information on gender, age, study year, basic health questions, participation in physical activity and other socio-demographic information.

To obtain information on breakfast and dietary intake for the previous day, a single 24-hour recall using the four-stage, multiple-pass method was conducted using food models and picture books to determine portion size. The dietary data were analysed using the South African Medical Research Council food composition tables and coded accordingly. ${ }^{18,19} \mathrm{~A}$ self-administered questionnaire was used to select the type of breakfast usually consumed by the adolescents. Breakfast was defined as any food or beverage consumed between $05 \mathrm{~h} 00$ and $10 \mathrm{~h} 00$ for the purposes of research. A "meal" was defined as an eating occasion, and was categorised as breakfast (05h0010h00), a morning snack (10h00-12h00), lunch (12h00-14h00 pm), an afternoon snack (14h00-18h00), dinner (18h00-20h00) and an evening snack (20h00-22h00).

Breakfast quality was measured through the allocation of a breakfast quality score, as described by Radcliffe et al. ${ }^{20}$ The scoring system was based on the five core food groups, as defined by the Australian Guide to Healthy Eating (AGHE), namely:

- Bread and cereal, including breakfast cereal, bread and rice.

- Vegetables.

- Fruit.

- Dairy products, including soya milk products.

- Meat and meat alternatives, including eggs, vegetarian meat alternatives and nuts.

The Diet Quality Index Revised (DQI-R) was used to assess the quality of the overall diet, and applied to all meals of the day, including breakfast. The DQI-R utilises a 100-point scale for a number of different indices or components of both food and nutrient measures of diet quality. ${ }^{21}$

Height and weight was measured by a level one anthropomotrist using the International Society for the Advancement of Kinanthropometry standards.

\section{Statistical analysis}

A standardised coding system was applied to each variable. SPSS $^{\circledR}$ was used to analyse the data. The association between breakfast intake and other categorical characteristics was assessed by either the chi-square test or Fisher's exact test. Spearman's rank correlation coefficient was used to assess the association between breakfast quality score and continuous variables. A p-value $<0.05$ was indicative of statistical significance.

The Goldberg cut-off, as defined by Black, ${ }^{22}$ was applied to exclude over- and under-reporters in this study, where the ratio of energy intake to basal metabolic rate (El: BMR) $=<0.6$ or $>4.91$.

\section{Ethical considerations}

The research proposal was approved by North-West University Research Ethics Committee (NWU-00031-13-A1). The study protocol was compliant with the guidelines outlined by the South African Medical Research Council general principles, and the international guidelines listed as the Helsinki Declaration, the Belmont Report and the Nuremberg Code. In addition, the research protocol was approved by the Department of Education in North West province, and permission to conduct the study was granted. Both written consent and assent were obtained from the parents or guardians, as well as adolescents, before commencement of the study. Participants could withdraw from the study at any point.

\section{Results}

Data were collected on 254 adolescents. Ten of them were found to be over- or under-reporters, and were excluded from the final data set in order to avoid skewed data. Complete dietary data were 
Table I: The demographic and anthropometric characteristics of the adolescents

\begin{tabular}{|c|c|c|c|c|c|c|c|c|c|}
\hline \multirow[t]{2}{*}{ Characteristics } & \multicolumn{3}{|c|}{ Total $(n=244)$} & \multicolumn{3}{|c|}{ Boys $(n=113)$} & \multicolumn{3}{|c|}{ Girls $(n=131)$} \\
\hline & Mean & SD & Median & Mean & SD & Median & Mean & SD & Median \\
\hline Age (years) & 17.5 & 2.3 & 17 & 17.6 & 2.6 & 17 & 17.4 & 1.9 & 17 \\
\hline $\mathrm{BMI}\left(\mathrm{kg} / \mathrm{m}^{2}\right)$ & 21.7 & 4.2 & 20.5 & 21.1 & 4.1 & 20.0 & 22.3 & 4.3 & 21.3 \\
\hline Weight (kg) & 58.8 & 13.0 & 56.3 & 60.8 & 14.5 & 57.4 & 57.0 & 11.4 & 54.7 \\
\hline Body fat $\%$ & 21.4 & 10.9 & 19.5 & 15.2 & 9.2 & 12.2 & 26.6 & 9.5 & 25.4 \\
\hline Total energy intake (kcal) & 2340 & 933 & 2170 & 2563 & 953 & 2421 & 2148 & 874 & 2031 \\
\hline Diet quality score & 58.2 & 9.9 & 57.8 & 58.1 & 10.1 & 57.6 & 58.3 & 9.4 & 58.9 \\
\hline Breakfast quality score & 3.1 & 1.2 & 3 & 3.1 & 1.3 & 3 & 3.1 & 1.2 & 3 \\
\hline
\end{tabular}

BMI: body mass index, SD: standard deviation

Table II a: Breakfast intake by demographic characteristics (chi-square test)

\begin{tabular}{|c|c|c|c|c|c|c|c|c|c|c|}
\hline \multirow[t]{2}{*}{ Breakfast intake } & \multicolumn{3}{|c|}{ Gender } & \multicolumn{4}{|c|}{ Grade } & \multicolumn{3}{|c|}{ Self-reported race } \\
\hline & $\begin{array}{c}\text { Female } \\
(n=131)\end{array}$ & $\begin{array}{c}\text { Male } \\
(n=113)\end{array}$ & p-value & $\begin{array}{c}9 \\
(n=74)\end{array}$ & $\begin{array}{c}10 \\
(n=75)\end{array}$ & $\begin{array}{c}11 \\
(n=95)\end{array}$ & p-value & $\begin{array}{c}\text { Black } \\
(n=197)\end{array}$ & $\begin{array}{l}\text { Other }^{*} \\
(n=47)\end{array}$ & p-value \\
\hline Skipped breakfast (\%) & 19.1 & 18.6 & 0.921 & 17.6 & 22.7 & 16.8 & 0.593 & 21.8 & 6.4 & 0.013 \\
\hline Consumed breakfast (\%) & 80.9 & 81.4 & & 82.4 & 77.3 & 83.2 & & 78.2 & 93.6 & \\
\hline
\end{tabular}

*: "Other" self-reported races included whites, Indians, coloureds

Table II b: Breakfast intake by demographic characteristics (chi-square test)

\begin{tabular}{|c|c|c|c|c|c|c|c|c|c|}
\hline \multirow[t]{2}{*}{ Breakfast intake } & \multicolumn{3}{|c|}{ Tobacco use ${ }^{*}$} & \multicolumn{3}{|c|}{ Alcohol use $^{\star \star}$} & \multicolumn{3}{|c|}{ Participation in physical activity } \\
\hline & $\begin{array}{c}\text { Yes } \\
(n=211)\end{array}$ & $\begin{array}{c}\text { No } \\
(n=30)\end{array}$ & p-value & $\begin{array}{c}\text { Yes } \\
(n=228)\end{array}$ & $\begin{array}{c}\text { No } \\
(n=14)\end{array}$ & p-value & $\begin{array}{c}\text { Yes } \\
(n=168)\end{array}$ & $\begin{array}{c}\text { No } \\
(n=73)\end{array}$ & p-value \\
\hline Skipped breakfast (\%) & 18.5 & 23.3 & 0.527 & 17.1 & 50.0 & 0.271 & 17.3 & 21.9 & 0.394 \\
\hline Consumed breakfast (\%) & 81.5 & 76.7 & & 82.9 & 50.0 & & 82.7 & 78.1 & \\
\hline
\end{tabular}

${ }^{*}$ Two breakfast eating participants did not indicate their smoking status

${ }^{\star}$ One breakfast eating participant did not indicate his or her alcohol consumption

${ }^{\star \star \star}$ Two breakfast eating participants and one breakfast skipping participant did not indicate their participation in physical activity

collected on 244 adolescents, and complete anthropometric data collected for 243. The final dataset of 244 adolescents was analysed for dietary data, and 243 adolescents for anthropometric data.

The mean age of the adolescents in the analysis sample was 17.5 years $( \pm 2.3$ years). Of the 244 study participants, 20 (8\%) were aged 21 years or older. Although these participants are not classified as adolescents, they were not excluded from the study as the factors and behaviour to which these individuals were exposed were the same as those for the adolescents included in the study sample. Of the analysis sample, $54 \%(n=131)$ were girls and $46 \%$ $(\mathrm{n}=113)$ boys. Table I details a summary of the demographic and anthropometric data for the adolescents who participated in the study.

Of the girls aged $14-20$ years, $21 \%$ had a body mass index (BMI) for age below the $25^{\text {th }}$ percentile, $34 \%$ a BMl for age above the $75^{\text {th }}$ percentile, and $45 \%$ a BMl for age between the $25^{\text {th }}$ and $75^{\text {th }}$ percentiles. Of the boys aged $14-20$ years, $47 \%$ had a BMl for age which fell below the $25^{\text {th }}$ percentile, $18 \%$ a BMl for age which fell above the $75^{\text {th }}$ percentile, and $35 \%$ a BMl for age which fell between the $25^{\text {th }}$ and $75^{\text {th }}$ percentiles. Twenty-one per cent of the study participants aged 21-26 years were underweight, and 16\% overweight.

\section{The prevalence of breakfast intake}

Of the total group, $81 \%$ of the adolescents had eaten breakfast the day before data collection, and $19 \%$ had skipped breakfast, as shown by the 24-hour recall. The demographic factors associated with the frequency of breakfast intake and skipping were analysed using the chi-square test. The results of this analysis are summarised in Table II $a$ and $b$. Of the girls surveyed $(n=131), 19.1 \%$ had skipped breakfast the day before data collection, compared to $18.6 \%$ of the boys surveyed $(n=113)$. Of the girls surveyed, $80.9 \%$ had eaten breakfast the day before data collection, compared to $81.4 \%$ of the boys who had eaten breakfast. There was no significant difference between the frequency of breakfast intake or skipping between gender ( $p$-value 0.921).A significant difference in breakfast intake was not observed between the grades ( $p$-value 0.593 ), alcohol use ( $p$-value 0.271$)$, tobacco use ( $p$-value 0.527 ) and participation in physical activity ( $p$-value 0.394$)$. Adolescents who self-classified themselves as "black" were observed to have a lower breakfast intake ( $p$-value 0.013 ) when compared to other groups. Individuals who self-classified themselves as coloured, Indian or white were grouped together, owing to the small numbers. 
Table III: Components of the breakfast quality score

\begin{tabular}{|c|c|c|c|}
\hline Breakfast quality score component & Scoring criteria & $\%$ study population & Total (n) \\
\hline No food or beverage (other than water), i.e. breakfast skipping & 1 & 20.1 & 49 \\
\hline A food or beverage from "extra" food only" & 2 & 7.0 & 17 \\
\hline A food or beverage from one AGHE group ${ }^{* *}$ & 3 & 25.0 & 61 \\
\hline A food or beverage from two AGHE groups ${ }^{* *}$ & 4 & 39.3 & 96 \\
\hline A food or beverage from three or more AGHE groups ${ }^{* * *}$ & 5 & 8.6 & 21 \\
\hline
\end{tabular}

\section{AGHE: Australian Guide to Healthy Eating}

${ }^{*}$ Considered to be a breakfast of low quality, e.g. examples include soft drinks, biscuits, cake, pancakes and chocolate bars, as well as high-fat savoury food, such as pastries, sausage rolls and vetkoek ${ }^{*}$ Considered to be a breakfast of moderate quality

${ }^{* \star}$ Considered to be of good breakfast quality

Table IV: Components of the Diet Quality Index Revised by breakfast intake and skipping

\begin{tabular}{|c|c|c|c|c|c|}
\hline Diet quality index component & Scoring criteria (\%) & Scoring $(\%)$ & $\begin{array}{l}\text { Total group mean score } \\
\text { (SD) }\end{array}$ & $\begin{array}{l}\text { Mean diet quality score } \\
\text { of the adolescents who } \\
\text { consumed breakfast }\end{array}$ & $\begin{array}{l}\text { Mean diet quality score } \\
\text { of the adolescents who } \\
\text { skipped breakfast }\end{array}$ \\
\hline \multirow[t]{3}{*}{ Total fat $\leq 30 \%$ energy intake } & $\leq 30=10$ & 48.0 & \multirow[t]{3}{*}{$7.4( \pm 2.5)$} & \multirow[t]{3}{*}{7.4} & \multirow[t]{3}{*}{7.2} \\
\hline & $>30$ to $\leq 40=5$ & 52.0 & & & \\
\hline & $>40=0$ & 0.0 & & & \\
\hline \multirow[t]{3}{*}{ Saturated fat $\leq 10 \%$ energy intake } & $\leq 10=10$ & 63.5 & \multirow[t]{3}{*}{$7.5( \pm 3.6)$} & \multirow[t]{3}{*}{7.6} & \multirow[t]{3}{*}{7.3} \\
\hline & $>10$ to $\leq 13=5$ & 23.4 & & & \\
\hline & $>13=0$ & 13.1 & & & \\
\hline \multirow{3}{*}{$\begin{array}{l}\text { Dietary cholesterol < } 300 \mathrm{mg} \\
\text { per day }\end{array}$} & $\leq 300=10$ & 73.0 & \multirow[t]{3}{*}{$7.7( \pm 3.9)$} & \multirow[t]{3}{*}{7.6} & \multirow[t]{3}{*}{8.4} \\
\hline & $>300$ to $\leq 400=5$ & 9.0 & & & \\
\hline & $>400=0$ & 18.0 & & & \\
\hline \multirow{3}{*}{$\begin{array}{l}2-4 \text { servings fruit per day, } \\
\text { (\% recommended servings) }\end{array}$} & $\geq 100$ & 4.9 & \multirow[t]{3}{*}{$1.6( \pm 0.7)$} & \multirow[t]{3}{*}{1.7} & \multirow[t]{3}{*}{1.2} \\
\hline & $50-99$ & 14.3 & & & \\
\hline & $<50$ & 80.7 & & & \\
\hline \multirow{3}{*}{$\begin{array}{l}\text { 3-5 servings vegetables per day }{ }^{* * *} \\
\text { (\% recommended servings) }\end{array}$} & $\geq 100$ & 5.3 & \multirow{3}{*}{$3.5( \pm 0.3)$} & \multirow[t]{3}{*}{3.3} & \multirow[t]{3}{*}{3.9} \\
\hline & $50-99$ & 24.2 & & & \\
\hline & $<50$ & 70.5 & & & \\
\hline \multirow{3}{*}{$\begin{array}{l}\text { 6-11 servings grains per day, } \\
\text { (\% recommended servings) }\end{array}$} & $\geq 100$ & 87.3 & \multirow[t]{3}{*}{$9.5( \pm 1.4)$} & \multirow[t]{3}{*}{9.5} & \multirow[t]{3}{*}{9.6} \\
\hline & $50-99$ & 11.1 & & & \\
\hline & $<50$ & 1.6 & & & \\
\hline \multirow{3}{*}{$\begin{array}{l}\text { Calcium intake as a percentage } \\
\text { of } \mathrm{Al} \text { for age }{ }^{* *}\end{array}$} & $\geq 100$ & 2.9 & \multirow[t]{3}{*}{$3.2( \pm 2.5)$} & \multirow[t]{3}{*}{3.4} & \multirow[t]{3}{*}{2.3} \\
\hline & $50-99$ & 18.9 & & & \\
\hline & $<50$ & 78.3 & & & \\
\hline \multirow{3}{*}{$\begin{array}{l}\text { Iron intake as a percentage of } \\
\text { RDA (1989) for age }\end{array}$} & $\geq 100$ & 59.0 & \multirow[t]{3}{*}{$8.7( \pm 1.9)$} & 8.9 & 7.9 \\
\hline & $50-99$ & 34.4 & & & \\
\hline & $<50$ & 6.6 & & & \\
\hline Dietary diversity score & $\geq 6$ & 0.0 & $2.5( \pm 1.0)$ & 2.6 & 2.1 \\
\hline & $\geq 3$ to $<6$ & 26.2 & & & \\
\hline & $<3$ & 73.8 & & & \\
\hline Dietary moderation score & $\geq 7$ & 42.6 & $6.6( \pm 1.6)$ & 6.4 & 7.1 \\
\hline & $\geq 4$ to $<7$ & 52.9 & & & \\
\hline & $<4$ & 4.5 & & & \\
\hline Total diet quality score & & & $58.3( \pm 9.9)$ & 59.0 & 57.0 \\
\hline $\begin{array}{l}\text { Al: adequate intake, RDA: recommended dietary } \\
{ }^{*} \text { Based on a } 1600 \mathrm{kcal}, 2200 \mathrm{kcal} \text { or } 2800 \mathrm{~kg} \\
{ }^{\star \star} \text { Used as a continuous variable } \\
{ }^{* \star} \mathrm{A} \text { maximum possible score of } 100\end{array}$ & $\begin{array}{l}\text { lowance, SD: standard deviation } \\
\text { diet }\end{array}$ & & & & \\
\hline
\end{tabular}




\section{Breakfast quality score}

The mean breakfast quality score for the study group was 3.1 $( \pm 1.27)$, with a maximum possible score of 5 and a minimum possible score of 1 . The breakfast quality score is based on the inclusion of food groups, as defined by the AGHE. A higher score indicates that food from more AGHE groups was included at breakfast and indicates better breakfast quality. Table III shows the breakfast quality scores for the study population. Breakfast quality scores of 4 and 3 were the most frequent, indicating a moderate-quality breakfast (a food or beverage from 1-2 groups from the AGHE, i.e. bread and cereal, vegetables, fruit, dairy or meat and meat alternatives were eaten at breakfast).

\section{Diet quality score}

The mean diet quality score for the study group was $58.3( \pm 9.85)$ out of a total possible score of 100 . Table IV shows the breakdown of DQI-R components for adolescents who consumed and skipped breakfast on the day of data collection. The maximum possible score for each of the DQI-R components was 10 . The recommended servings of fruit per day (mean score of 1.6), dietary diversity (mean score of 2.5), adequate intake of calcium (mean score of 3.2) and recommended servings of vegetables per day (mean score of 3.5) were the components of the DQI-R which showed the lowest mean scores for the study sample. The recommended servings for grain per day (mean score of 9.5) and the recommended daily allowance for iron (mean score of 8.7) were the components which showed the highest mean scores.

\section{The effect of breakfast intake and the breakfast quality score on diet quality score and lifestyle behaviour}

In this study, adolescents who self-classified themselves as "black" were observed to have lower breakfast intake ( $p$-value 0.013 ) and

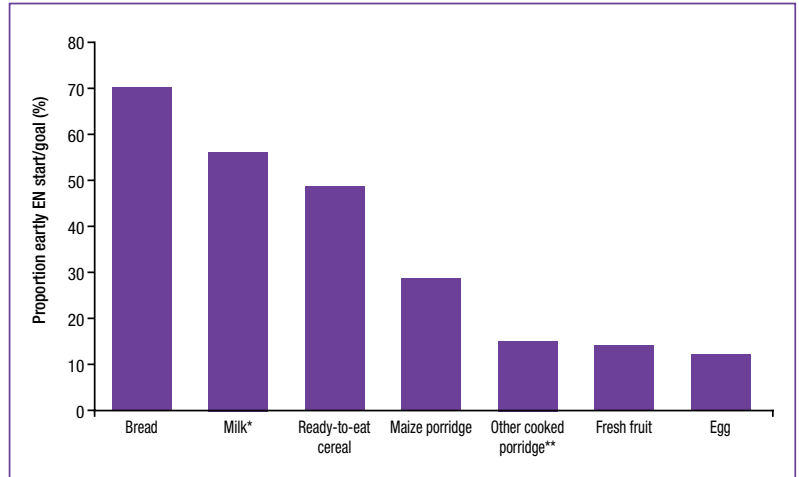

* Only included for servings of $100 \mathrm{ml}$ or more

${ }^{\star *}$ Made up of cooked maltabella (sorghum porridge) and cooked oats

Figure 1: Frequency of intake of different breakfast foods by the adolescents

lower breakfast quality score ( $p$-value 0.0001 ) than the other groups. Adolescents participating in physical activity were significantly more likely to have a higher breakfast quality score than inactive participants (p-value 0.007). Breakfast quality was not associated with age ( $p$-value 0.585$)$, grade ( $p$-value 0.734 ), alcohol use ( $p$-value $0.152)$ or tobacco use ( $p$-value 0.737$)$.

The mean diet quality score for breakfast eaters was 59 , while the mean score for breakfast skippers was 57 . There was no significant difference in the diet quality score between the adolescents who consumed and skipped breakfast. A correlation between breakfast quality score and diet quality score was not found $(r=0.040$, $p$-value 0.533). However, it was observed that certain components of the DQI-R increased with an increase in breakfast quality score, although the strength of the correlation indicated a trend rather than a proportionate relationship. The components of the DQI-R that were influenced by breakfast quality score were adequate intake

Table V: The nutrient composition of foods commonly consumed at breakfast

\begin{tabular}{|c|c|c|c|c|}
\hline Nutrient & $\begin{array}{l}\text { Brown bread (fortified) } \\
\text { (60 g serving) }\end{array}$ & $\begin{array}{l}\text { Low-fat milk } \\
\text { (125 g serving) }\end{array}$ & $\begin{array}{c}\text { Ready-to-eat ceral } \\
\text { (cornflakes*) (40 g serving) }\end{array}$ & $\begin{array}{l}\text { Maize meal (fortified, soft, } \\
\text { cooked) (250 g serving) }\end{array}$ \\
\hline Energy (kJ) & 649.0 & 266.0 & 642.0 & 585.0 \\
\hline Protein (g) & 5.2 & 4.1 & 3.1 & 3.0 \\
\hline Carbohydrates (g) & 26.5 & 6.1 & 33.1 & 28.5 \\
\hline Sugar (g) & 0.0 & 6.1 & 2.5 & 0.0 \\
\hline Fat $(g)$ & 1.2 & 2.5 & 0.1 & 0.8 \\
\hline Saturated fat $(\mathrm{g})$ & 0.2 & 1.6 & 0.0 & 0.3 \\
\hline Cholesterol (mg) & 0.0 & 8.8 & 0.0 & 0.0 \\
\hline Dietary fibre (g) & 4.0 & 0.0 & 1.3 & 1.3 \\
\hline Sodium (mg) & 271.0 & 58.0 & 484.0 & 0.0 \\
\hline Thiamine (mg) & 0.1 & 0.0 & 0.5 & 0.1 \\
\hline Riboflavin (mg) & 0.0 & 0.2 & 0.6 & 0.0 \\
\hline Niacin (mg) & 1.6 & 0.1 & 7.1 & 0.3 \\
\hline Folic acid $(\mu \mathrm{g})$ & 25.2 & 6.3 & 100.0 & 5.0 \\
\hline Calcium (mg) & 33.0 & 152.5 & 4.4 & 0.0 \\
\hline Iron (mg) & 0.9 & 0.1 & 4.8 & 0.3 \\
\hline Phosphorous (mg) & 104.4 & 111.3 & 20.4 & 60.0 \\
\hline
\end{tabular}

*Cornflakes were the most frequently consumed ready-to-eat cereal in the study group 
for calcium ( $r=0.418, p$-value $<0.0001)$, total diversity score $(r=0.369, p$-value $<0.0001)$ and meat diversity score $(r=0.503$, $\mathrm{p}$-value $<0.001)$. An increased breakfast quality score also showed a trend for an increased intake of certain nutrients, namely calcium $(r=0.418, p$-value $<0.0001)$ and phosphorous $(r=0.378$, $p$-value $<0.0001)$.

\section{Foods most frequently consumed for breakfast}

In order to explain the trends observed with respect to the diet quality score, the most frequently consumed foods at breakfast were investigated. Bread, milk, ready-to-eat cereals and maize porridge were the most frequently consumed foods at breakfast (Figure 1). Added sugar was consumed by 140 of the adolescents at breakfast, and was consumed in an average serving size of $19 \mathrm{~g}$. Margarine was consumed by 42 of the adolescents at breakfast in an average serving size of $14 \mathrm{~g}$. The beverages most frequently consumed at breakfast were tea $(n=74)$, water $(n=45)$ and coffee $(n=32)$.

The nutrient composition of bread, milk, ready-to-eat cereal and maize are provided in Table $\mathrm{V}^{18,19}$ Notably, the most frequent breakfast formats usually consumed, as reported in the selfadministered questionnaires by the study group, were "porridge only, with a drink" (81\%), followed by "bread, toast, a roll or crisp bread with a drink" $(77 \%)$.

\section{Discussion}

The main findings of this study were as follows:

- Nineteen per cent of the adolescents skipped breakfast.

- Breakfast intake and quality did not significantly affect overall diet quality.

- The intake of certain foods at breakfast may have contributed valuable nutrients to the diet.

The present study found that $81 \%$ of adolescents ate breakfast and $19 \%$ skipped it. When this figure is compared to international data, the prevalence of breakfast skipping in our study appears to be moderate. International data indicate that breakfast skipping behaviour is as high as $79.7 \%$ in black adolescents in the USA, as reported by Delva, 0'Malley and Johnston, ${ }^{23}$ and as low as $7 \%$ in adolescents in the UK, as reported by Sandercock, Voss and Dye. ${ }^{24}$

Research, in which breakfast behaviour in adolescents in South Africa is reported, is limited, although the South African National Health and Nutrition Examination Survey (SANHANES), published in 2013 , also indicated that $19 \%$ of children aged $10-14$ years did not eat breakfast before going to school. ${ }^{25}$ Examined by province, the SANHANES reported that $22.9 \%$ of children in North West province did not eat breakfast before school, and that children in the Western and Eastern Cape were significantly more likely to eat breakfast than those in the North West, Gauteng and Limpopo provinces. ${ }^{24,25}$

Steyn and Temple ${ }^{11}$ showed that $22 \%$ of adolescents attending secondary schools in Cape Town skipped breakfast, and similarly, Feeley et al ${ }^{10}$ demonstrated that the prevalence of breakfast skipping in Soweto, Gauteng was $24 \%, 36 \%$ and $35 \%$, for adolescents aged 13,15 and 17 years, respectively. This suggests that the prevalence of breakfast intake in adolescents in South Africa differs by province, and possibly according to the environment in which the adolescents are exposed. South Africa is undergoing a period of unique nutrition transition, driven by aspects of economic globalisation, such as urbanisation, changes in income and economic upliftment, and the Westernisation of readily available foods, industry and marketing behaviour. ${ }^{26,27}$ The nutrition transition is transforming the landscape of food that is available to the public, and may be influencing food and dietary choices in adolescents. According to Feeley et al, ${ }^{10}$ breakfast skipping, as well as other poor lifestyle habits, may be reflective of the context in which South African adolescents live. It would be valuable to understand the drivers behind breakfast skipping behaviour within different adolescent population groups in South Africa.

The Integrated School Health Policy (ISHP) of South Africa is the first joint policy between the Departments of Health and Basic Education, and focuses on identifying and managing health barriers to learning in children in state schools in South Africa. ${ }^{28}$ The ISHP seeks to enhance existing health programmes in state schools, and build a comprehensive and holistic health-promoting programme through the cross-collaboration of governmental departments and key stakeholders within the teaching environment. ${ }^{28}$ Nutrition has been highlighted as a key focus area within the ISHP, including nutrition education and enhancement of the National School Nutrition Programme (NSNP) which provides nutritious meals to learners in need.

The findings of the present study provide some insight into the implementation of the ISHP in North West province.

The South African Department of Basic Education has implemented the NSNP in lower-income primary and secondary schools. ${ }^{24,29}$ According to the policy, a nutritious meal should be served to learners by $10 \mathrm{~h} 00.24,29$ The schools in quintiles 1-4 that were included in this research all benefited from the NSNP, whereas schools in quintile 5 did not. On further investigation, it was found that the NSNP meal was actually being served at $11 \mathrm{~h} 00$, and was thus classified as a "morning snack", rather than "breakfast" for the purposes of the research. Receiving this meal before $10 \mathrm{~h} 00$ would have improved the breakfast quality score for these adolescents, but since it was only received at $11 \mathrm{~h} 00$, the NSNP meal only affected the diet quality score in these groups. Given the identified benefits of breakfast, and the prevalence of breakfast skipping in adolescents in North West province, the provision of a breakfast meal is important in this target group. Therefore, there is an opportunity to improve NSNP meal delivery to these schools, to ensure that the meal is served before $10 \mathrm{~h} 00$, as per the policy requirements.

There was a lower breakfast intake prevalence and a lower breakfast quality score in black adolescents in this study, compared to that found in the other races. Similar findings have been observed in international research. Breuning et $\mathrm{al}^{16}$ summarised the predictors of breakfast consumption in adolescents in the USA, and found that non-white groups were less likely to consume breakfast than white groups ( $p$-value $<0.01$ ). Delva, O'Malley and Johnston ${ }^{23}$ reported 
a trend of less frequent breakfast intake in black and Hispanic youth, when compared to white youth in the USA, although this finding was not significant. While self-reported race alone cannot explain the differences observed in breakfast intake and quality, it is possible that cultural exposure within different race groups may influence breakfast-eating behaviour. Further research is required to understand cultural attitudes and perceptions towards breakfast intake, which may potentially explain the differences observed between the different race groups.

Participation in physical activity was associated with improved breakfast quality. To our knowledge, the relationship between breakfast quality and physical activity has not been reported in any study, although a positive relationship for breakfast intake and increased physical activity has been observed ( $p$-value $\leq 0.001$ ). . $^{24,30-}$ ${ }^{32}$ In the present study, participation in physical activity did not differ between adolescents who consumed or skipped breakfast. This highlights the need to investigate the role of breakfast quality, as well as breakfast intake, in influencing subsequent activity levels for the day.

It was hypothesised that breakfast intake and a higher breakfast quality score would result in a higher diet quality score for the adolescents for the day. The present study found no significant difference in the diet quality score between the adolescents who consumed, and those who skipped, breakfast. A correlation between the breakfast quality score and diet quality score was not found. The breakfast quality score and components of the DQI-R were marginally associated, indicating a trend of improved calcium intake, dietary diversity score and meat diversity score. When comparing the mean scores for components of the DQI-R (Table IV) between the adolescents who ate and those who skipped breakfast, breakfast skippers had a lower (less favourable) mean score for calcium and iron intake, and a higher (more favourable) mean score for cholesterol intake.

When examining the foods most frequently consumed for breakfast; bread, milk and ready-to-eat cereal were the most prevalent foods. Nutrition analyses of these foods show that they are valuable contributors to certain nutrients in the diet. ${ }^{18,19}$ Milk is a significant contributor of calcium to the diet. ${ }^{33}$ The present study showed that adolescents who consumed breakfast were more likely to consume milk, thus explaining the observed trend for increased calcium intake in the breakfast-eating group. The DQI-R component of the "meat diversity score" classified milk as a "meat" due to its high protein content, which meant that adolescents who ate breakfast in this study were more likely to have milk, because of their choice of breakfast. This means that they also had a slightly higher mean meat diversity score. The meat diversity score was one of the major contributors to the total diversity score. Therefore, the consumption of milk by the breakfast eaters explained the trend between the increased breakfast quality score, increased calcium intake, increased meat diversity score and total diversity score. Of the most frequently consumed foods at breakfast, milk was the only contributor to cholesterol. Again, the consumption of milk by breakfast eaters may explain the tendency for a higher cholesterol intake in breakfast eaters than in breakfast skippers.

It is mandatory to fortify all white and brown bread flour and maize meal with vitamin A, thiamine, riboflavin, niacin, folic acid, pyridoxine, iron and zinc in South Africa. ${ }^{34}$ The consumption of these foods helps to increase the intake of these nutrients which are lacking in the diet of many South Africans. ${ }^{35}$ Given that bread and maize were two of the most frequently consumed foods at breakfast, the iron content of these foods, as part of the national fortification mandate, may explain the tendency for a higher iron intake in breakfast eaters, when compared to breakfast skippers. Ready-to-eat cereal is typically fortified with iron, as well as other nutrients, and may also have contributed to the iron intake of the breakfast-eating group. Brown bread, milk and maize meal also contain phosphorous, which helps to explain the trend for increased phosphorous intake in the breakfast-eating group. ${ }^{18}$

The strength of this study was that the total number of included participants created adequate power with which to draw valid conclusions from the results of this research, including the determination of accurate means and standard deviation, and to be able to compare the quintiles with one another. However, limitations should also be taken into account when interpreting these results. The study's cross-sectional study design allowed for an understanding of the relationships and associations around breakfast intake and quality, but did not establish causality between these variables. It is possible that the behaviour observed by quintile may be attributed to socio-environmental factors, including the school culture and environment. Including more schools from each quintile would have provided a better representation of the socio-economic background. More specific questions, including a qualitative assessment, could also be used to address attitudes, behaviour, socio-economic status and food security. Lastly, the breakfast intake behaviour was determined from one 24-hour recall and did not reflect the usual breakfast intake.

\section{Conclusion and the implications for research and practice}

The role of breakfast in improving nutrient intake and diet quality, as well as decreasing the risk of obesity and chronic diseases in adolescents, has been well documented in international research. This study shows that $19 \%$ of the adolescents did not eat breakfast the day before data collection, meaning that they missed an opportunity to improve their health outcome.

The quality of the breakfast consumed by the adolescents in the present study was moderate, highlighting an opportunity for intervention to improve breakfast intake and quality in this target group.

The findings of the current study suggest that cultural and socio-environmental factors may influence breakfast intake and breakfast quality. Thus, further research is required to facilitate an understanding of how different cultural and environmental factors, 
as well as individual attitudes and perceptions towards breakfast, influence breakfast behaviour in South African adolescents.

While breakfast intake did not influence the diet quality of the adolescents, it was shown that the intake of certain foods at breakfast helped to improve the mean scores for some components of the DQI-R, and helped to improve the intake of key nutrients.

It is recommended that the governmental departments responsible for the ISHP incorporate breakfast messaging into the nutrition education component of the ISHP. Facilitators involved in implementing the ISHP, such as school-based support teams, teachers and healthcare professionals, are encouraged to continue the promotion of breakfast intake by adolescents, in order to entrench breakfast intake behaviour which will continue into adulthood, and thereby improve health outcomes in the long term.

\section{Acknowledgements}

This research was co-funded by the Kellogg Company of South Africa and North-West University. The Kellogg Company of South Africa did not in any way influence the study design, data collection, analysis or interpretation of the data, the writing of the report or the decision to submit the article for publication. The authors wish to acknowledge Lianri Swanepoel for providing support during the data collection, and Prof Edelweiss Wentzel-Viljoen for providing guidance in the interpretation of the results.

\section{References}

1. Kruger H, Dhansay M, Labadarios D, et al. The importance of breakfast in meeting nutritional requirements of South African children. S Afr J Clin Nutr. 2002;15(1):5-12.

2. Barton BA, Eldridge AL, Thompson D, et al. The relationship of breakfast and cereal consumption to nutrient intake and body mass index: the National Heart, Lung, and Blood Institute Growth and Health Study. J Am Diet Assoc. 2005;105(1383-1389).

3. Hoyland A, Dye L, Lawton CL. A systematic review of the effect of breakfast on the cognitive performance of children and adolescents. Nutrition Research Reviews. 2009;22(2):220-243

4. Smith KJ, Gall SL, McNaughton SA, et al. Skipping breakfast: Iongitudinal associations with cardiometabolic risk factors in the Childhood Determinants of Adult Health Study. Am J Clin Nutri. 2010;92(6):1316-1325

5. Deshmukh-Taskar PR, Nicklas TA, O'Neil CE, et al. The relationship of breakfast skipping and type of breakfast consumption with nutrient intake and weight status in children and adolescents: The National Health and Nutrition Examination Survey 1999-2006. J Am Diet Assoc. 2010;110(6):869-878.

6. Rampersaud G, Pereira M, Girard B, et al. Breakfast habits, nutritional status, body weight and academic perfomance in children and adolescents. J Am Diet Assoc. 2005;105(5):743-760.

7. Seiga-Riz AM, Popkin BM, Carson T. Differences in food patterns at breakfast by sociodemographic characteristics among a nationally representative sample of adults in the United States. Prev Med. 2000;30(5):415-424

8. Cho S, Dietrich M, Brown C, et al. The effect of breakfast type on total daily energy intake and body mass index: results from the Third National Health and Nutrition Examination Survey (NHANES III). J Am Coll Nutr. 2003;22(4):296-302.

9. Walker A, Walker B, Jones J, Ncongwane J. Breakfast habits of adolescents in four South African populations. Am J Clin Nutr. 1982;36(4):650-656.

10. Feeley A, Musenge E, Pettifor JM, Norris SA. Changes in dietary habits and eating practices in adolescents living in urban South Africa: The birth to twenty cohort. Nutrition. 2012;28(7-8):e1-e6.
11. Temple NJ, Steyn NP, Myburgh NG, Nel JH. Food items consumed by students attending schools in different socioeconomic areas in Cape Town. Nutrition. 2006;22(3):252-258.

12. Frech $A$. Healthy behaviour trajectories between adolescence and young childhood. Advances in Life Course Research. 2012;17(2):59-68.

13. Niemeier HM, Raynor HA, Lloyd-Richardson EE, et al. Fast food consumption and breakfast skipping: predictors of weight gain from adolescence to adulthood in a nationally representative sample. J Adolesc Health. 2006;39(6):842-849

14. Merten MJ, Williams AL, Shriver LH. Breakfast consumption in adolescence and young adulthood: parental presence, community context, and obesity. J Am Diet Assoc. 2009;109(8):1384-1391.

15. Ortega RM, Requejo AM, Navia B, Andres $P$, et al. The relationship between the consumption of an inadequate breakfast and energy profile imbalance in preschool children. Nutrition Research. 1998;18(4):703-712.

16. Breuning M, Larson N, Story M, et al. Predictors of adolescent breakfast consumption: longitudinal findings from project EAT. J Nutr Educ Behav. 2011;43(5):390-395.

17. Pendlebury S, Lake L, Smith C, editors. South African child gauge 2008/2009. Cape Town: Children's Institute, University of Cape Town, 2009.

18. Wolmarans P, Danster N, Dalton A, et al. Condensed food composition tables for South Africa. Parow Valley: Medical Research Council, 2010.

19. Langenhoven M, Conradie P, Wolmarans P, Faber M. Food quantities manual. Parow Valley, Cape Town: Medical Research Council; 2002.

20. Radcliffe B, Ogden C, Coyne T, Craig P. Breakfast consumption patterns of upper primary schools students in 14 Queensland schools. Nutr Diet. 2004;61(3):151-158.

21. Haines PS, Siega-Riz AM, Popkin BM. The Diet Quality Index Revised: a measurement instrument for populations. J Am Diet Assoc. 1999;99(6):697-704.

22. Black A. Critical evaluation of energy intake using the Goldberg cut-off for energy intake: basal metabolic rate. A practical guide to its calculation, use and limitations. Int J Obes Relat Metab Disord. 2002; 24(9):1119-1130.

23. Delva J, O'Malley PM, Johnston L. Racial/ethnic and socioeconomic status differences in overweight and health-related behaviours among American students: national trends 1986-2003. J Adolesc Health. 2006;39(4):536-545.

24. Sandercock G, Voss C, Dye L. Associations between habitual school-day breakfast consumption, body mass index, physical activity and cardiorespiratory fitness in English schoolchildren. Eur J Clin Nutr. 2010;64(10):1086-1092.

25. Shisana 0, Labadarios D, Rehle T, et al. South African National Health and Nutrition Examination Survey (SANHANES-1). Cape Town: HSRC Press, 2013

26. Steyn K, Fourie J, Temple N. Chronic diseases of lifestyle in South Africa: 1995-2005. Cape Town: South African Medical Research Council, 2006.

27. Stupar D, Eide WB, Bourne L, et al. The nutrition transition and the human right to adequate food for adolescents in the Cape Town metropolitan area: Implications for nutrition policy. Food Policy. 2012;37:199-206.

28. Department of Health, Department of Basic Education. Integrated School Health Policy, 2012

29. Department of Basic Education. National School Nutrition Programme Annual Report, 2012.

30. Tin SPP, Ho SY, Mak KH, et al. Lifestyle and socioeconomic correlates of breakfast skipping in Hong Kong primary 4 schoolchildren. Prev Med. 2011;52(3):250-253.

31. Keski-Rahkonen A, Kaprio J, Rissanen A, et al. Breakfast skipping and health compromising behaviours in adolescents and adults. Eur J Clin Nutr. 2003;57(7):842-853

32. Schembre SM, Wen CK, Davis JN, et al. Eating breakfast more frequently is crosssectionally associated with greater physical activity and lower levels of adiposity in overweight Latina and African American girls. Am J Clin Nutr. 2013;98(2):275-281.

33. Dairy Council. Dairy foods: a major nutrient contributor to Americans' diets. Dairy Council Digest Archives. 2011;82(5):1-6

34. Regulations relating to the fortification of foodstuffs. Foodstuffs, Cosmetics and Disinfectants Act, 1972;4-62. Pretoria: Government Gazette, 2002. [homepage on the Internet]. c2015. Available from: http://www.gov.za/sites/www.gov.za/ files/23714_1055.pd

35. Steyn N, Wolmarans P, Nel J, Bourne L. National fortification of staple foods can make a significant contribution to micronutrient intake of South African adults. Public Health Nutr. 2008;11(3):307-313. 